\title{
CVT Connect: Creating safe and accessible social media for people with learning disabilities
}

Peter Williams ${ }^{1}$ and Philip Gibson ${ }^{2}$

${ }^{1}$ Department of Information Studies, University College London, Gower Street, London, WC1E 6BT Corresponding author: +44(0)7963412368 peter.williams@ucl.ac.uk

${ }^{2}$ Camphill Village Trust, 9 Saville Street, Malton, North Yorkshire, England, YO17 7LL

\section{Abstract}

BACKGROUND: Camphill Village Trust (CVT) is a National charity, supporting around 500 adults with learning disabilities in community settings.

OBJECTIVE: To co-design a social media platform to enable people supported at CVT to enjoy the benefits social media can offer, in a 'safe space'.

METHODS: A survey was undertaken of potential users to determine existing technology use and what was wanted from a social media platform. This was constructed according to findings, and solo and group interviews and another survey captured usage and opinions.

RESULTS: Posting and reading the posts of others were popular, but use of other facilities (e.g. noticeboard) was limited. People valued its role as a social connector, and the closed environment was also seen as a benefit. Staff used it to aid social interactions and as a learning tool. Barriers included remembering passwords, uploading photos and lack of support, the latter due to competing time demands on staff.

CONCLUSIONS: The study showed that it is possible to involve people with learning disabilities in the development of an electronic resource, and that a safe, protected platform can be utilised for both entertainment and education. Some staff were reticent, which highlighted the need for training and time allocation.

Keywords: learning disabilities, social media, co-production 


\section{CVT Connect: 'Creating safe and accessible social media for people with learning disabilities}

\section{Introduction}

Camphill Village Trust (CVT) is a National charity, supporting around 500 people, mostly adults with learning disabilities, community settings in a mixture of urban and rural locations. In addition to supported living accommodation it assists people in a variety of working environments to develop skills to enable them to make a positive contribution to the local community. The Trust wanted to explore how people with learning disabilities could co-design a social media platform that would not only enable them to network with others but also allow people to develop the social-media skills they need in a 'safe space' with support and advice when needed.

Social media was already impacting the lives of the people CVT supports. Indeed, it has become ubiquitous throughout our society. In the UK, according to Battisby [1] there are now 45 million social media users in the UK. This equates to $67 \%$ of the entire population. However, Durragh et al [2] point out that for people with learning disabilities, 'social media remains inaccessible due to the design and functionality of various applications, lack of computer or device access, as well as poor or limited literacy skills'. However, social media technology, if configured to be accessible for this cohort, could be used as part of a strategy to tackle social isolation and make significant improvements to the quality of life people with learning difficulties experience, and be used by families and carers as a way to keep in touch. The aims of the platform (to be named 'CVT Connect') were to create a digital platform where:

- people with learning difficulties could connect together and share ideas, and thus reduce the social isolation often experienced by the cohort;

- staff and the people they support can work together using technology;

- skills are developed that help people to use social media in a safer environment.

\section{Literature review}


Considering the usage statistics cited above, the paucity of literature on the use of social media by people with learning disabilities is surprising. A comprehensive literature review by Caton and Chapman [3] found 10 relevant articles, fitting their criteria of 'describ(ing) a primary research study exploring the use of social media by people with intellectual disability' (p126). However, articles included many only peripherally concerned with the day-to-day activities of the cohort in using social media, such as Kydland et al's [4] account of teaching participants to use Flickr and Molin et al's [5] survey of parents' and teachers' views on young people 'with intellectual disabilities' and their opportunities for and barriers to using the Internet. More relevant is a study by Holmes and O'Loughlin, [6] who explored experiences of three people with learning disabilities using social networking sites. One participant had difficulties because of her 'concrete understanding of the word "friend" as used by Facebook. Because of this, she "would attend parties ... arranged on Facebook by "friends" whom she had never met before, placing her in potentially ... vulnerable situations' (p5). Another suffered from 'social anxiety'. For her 'Facebook provided ... a medium in which to increase her social circle without having to meet anyone,' (p5). The third participant was pleased to be able to 'keep in touch with people she had been to school with, and update them on what she was doing now'. (p6)

Shpigelman and Gill [7] examined 'how adults with intellectual disabilities participate in ... Facebook'. An 'accessible' online survey was undertaken, distributed through Facebook pages, regarding users' experiences, capabilities, and preferences. Results (from 58 respondents) suggested that these Facebook users were less-frequent users of Facebook - 'at least once a week' as compared to 'at least once a day' for the general Facebook-using population. This was said to be due to problems with reading and writing and the usability difficulties of the web in general and of Facebook in particular. Perhaps surprisingly, there were no significant differences between the frequency of using Facebook between those who lived alone or with others. Sixty eight percent of the respondents said that making new friends is easier on Facebook than face to face, and $26 \%$ reported that by using Facebook they feel 'like everyone else.' 
Daems, et al [8] undertook focus groups with 23 people with learning disabilities to discuss their knowledge of social media and what technological alterations would help them. Facebook and Skype were used, although using social media, 'seemed to be harder' than 'watching clips or listening to music' (p78). This was because of problems in spelling and ineffective speech to text software, rendered less effective by participants being unable to articulate clearly.

Finally, and of particular relevance to the initiative reported here, Blanco, Marco and Casas [9] describe 'the design, development and deployment of an Online Social Network (OSN) ... in a residence for people with [cognitive] disabilities in order to improve productivity, enhance the quality of care processes and foster social relations'. The OSN contained components such as a blog, discussion, events notification, messages, gallery (allowing users to upload photos) and video (allowing the viewing of external sources such as YouTube). However, the platform was designed more for relatives and staff, and the paper concentrates extensively on the technical aspects of its construction and its exploitation by these groups. Usage was initially measured by 'analysing the platform activity records ... (session log in/out, contents creation, adding comments, etc.), which allows an analysis to be conducted of ...level of activity, operations performed ... [etc.]' After collating the results, focus groups of users were undertaken to complement and contextualise results and to discover any 'unexpected and emotional issues' (p324). Residents' use was tutored and controlled, such that they 'just sent one private message to relatives in a classroom'. In fact, only three residents and their respective families undertook full participation, described as being due to the cognitive limitations of nearly all of the residents, although many others undertook 'computer classes' which included access to the OSN's picture galleries. The paper claims, albeit without presenting appropriate evidence, that they were 'very motivated to use the OSN'.

In sum, very little research appears to have been undertaken on the use of social media by this particular cohort, and even less on examining either 'naturalistic' use (instead describing the introduction of and instructions of how to use platforms [4); exploitation by [9] or opinions of those in support roles [5]. Only one paper [9] offered an account of the development of a social media 
platform, but - as mentioned - this was designed more for support workers, and produced to aid professional communication. Thus, CVT Connect itself, and the documentation and research around its development and implementation fills an important gap in the field.

\section{Creating and developing CVT Connect}

Before describing the creation and development of CVT Connect in detail, it is important to mention that the process had coproduction at its core. This was on the basis being that people who use a service are best placed to create, change or improve that service. The creation and development of a digital platform involved people with disabilities at nearly every stage since. Indeed, the only areas that people with disabilities did not play the key role were in the actual technological build.

\subsection{Phase one - scoping and prototype}

The first stage in the development of CVT Connect was to explore how people with LD get and share the information they need to make choices and how they then communicate these choices. To this end we undertook a survey of people we support to determine how many people had access to or were using smart phones, tablets, laptops and PC's. Results showed that nearly $50 \%$ were already using these devices, with varying degrees of support.

We asked what people were doing on their devices. These fell into three main categories: keeping in contact with family / friends (including via social media), finding information and using phone apps the latter usually quite simple, for recreation, and often being aimed at young children. Problems encountered included the hardware or software being too complex, login problems, online bullying and being victim of or fearing online scams.

In addition to taking these problems into account, we also asked what people wanted from a digital social media platform. Many said they would like something where they could connect with their friends / people they know. Specifically, they sought a system that:

- Had an easy login system 
- Was not as 'open and large' as Facebook

- Helped in acquiring skills / confidence on-line with the support of people they knew and trusted. This was principally in order to engage with other forms of social media / technology, such as Facebook, Instagram, etc., without experiencing the problems reported in the scoping study. Following this phase, a group of 12 people with learning disabilities started working with Made Open, a digital communications company, to produce a closed, accessible social media platform that attempted to meet the needs outlined above. Six months later (March 2016) CVT Connect was launched. It enabled users to:

- Create a personal profile they could share with others

- Collaborate through shared project 'walls' (created by administrators)

- Find Information on digital noticeboards

Other features included:

- A closed network for people supported and staff. This could be done in a 'safe' way as the network is restricted to people supported by or work for CVT.

- Local administration and moderation, which helped ensure safety as the administrators already know and work with each person;

- A picture password sign-up option;

- Easy read help pages at every stage;

- Limited choices / pathways at every stage.

After an initial level of interest, an informal audit in May 2018 found that the numbers of people actively using CVT Connect was very low, around 15 regular users, representing only $3 \%$ of the possible user population. This low take-up prompted a review of the platform. Interviews were undertaken with the few existing users; people who had tried but since stopped, and those who had never registered. Two focus groups of around eight participants each participated in this exercise. Such group interviews 'have the advantages of a group dynamic that can help build confidence, safe 
environments that are not threatening or intimidating and peer support and validation, all enabling people with learning difficulties to contribute to research discussions'. [10] (p76).

Findings were that:

- The system, despite being created to be suitable for the cohort, was still too complex for people to sign up. An email address was required to login and for sending password reset links. This was often needed as people forget passwords regularly - even pictorial ones;

- It needed staff to invest time on the initiative, but they have competing duties which took priority. They also did not see the potential benefit to the people they supported;

- Like all social media, it needed a critical mass of users to make it engaging and interesting. Low sign up stopped this happening;

- The site needed to be easier to navigate and find what was happening. To this end, facilities to 'notify' and 'signpost' users was required, to alert them to any activity since they had last logged in.

\subsection{CVT Connect Version 2}

These changes were discussed with Made Open. Table One summarises aspects of identified as requiring attention, the particular problems to be addressed, and the solutions implemented:

\section{Table one here}

In addition to the changes made to the platform the most significant development was the funding of time so the local administrators could show staff and the people they support the platform, assist them to create an account and explore what they can do.

Figure One, below, shows the process from the concept of CVT Connect to the evaluation of the current version (2) of the platform.

Figure One here 
CVT Connect was re-launched on November $1^{\text {st }} 2018$, with all existing accounts reset to enable a completely fresh start.

\section{Evaluation of the new CVT Connect}

CVT was already working with UCL as a participating learning disabilities organisation on a Postdoctoral research project being carried out by one of the authors (Williams) examining the use and impact of digital technology on the lives of people with learning disabilities. (see, e.g. [11], [12], [13]) It was decided to incorporate a formal evaluation of CVT Connect as part of this work.

\section{4. `1 Methodology}

Sample and recruitment: All participants were from the CVT. Two CVT communities (as they are known) were chosen for participation, on the grounds of staff/participant interest and contrasting locations (one rural one urban). The people supported, by definition, were considered to have learning disabilities. For inclusion as study participants they needed to be familiar with a web browser (not necessarily using CVT Connect) and able to understand questions around their use of devices, the World Wide Web and apps etc. This was generally achieved by self-selection, where those either participating in general computer-related activity sessions, or specific CVT Connect training workshops were given a briefing about the project and invited to participate. Others, whom support staff considered to fit the criteria were also invited. In addition, six support staff also participated, being interviewed about their experiences of working on CVT Connect and mobile technology generally with the cohort.

Methods: Two methods to gather data were used: an online survey and face to face interview and observational sessions. Most of the latter were undertaken in small groups, for the reasons cited above. However, some individuals preferred to be interviewed alone - usually, in fact, based simply on availability and convenience. Most sessions occurred during existing group computer or CVT Connect sessions. Questions were very broad, and covered topics concerning use (devices, apps etc. 
as well as of CVT Connect); benefits, barriers and, in the case of CVT Connect, how the platform could be improved.

It is worth noting that particular care needs to be taken when working with this cohort, in terms of participant understanding of questions and, indeed, of the wider research aims [14]. As the latter were concerned with the practical issue of improving the electronic resource with which the participants were familiar, this did not present a problem. Regarding the interviews themselves, the interviewer (Williams) was cognisant of Prosser and Bromley's much cited 'checklist' of how to interview people with learning disabilities [15]. It includes the following recommendations for prospective interviewers:

- Use: short words, single-clause sentences, active verbs and the present tense when possible;

- Avoid: abstract concepts, figurative or colloquial language.

In asking about opinions, which accounted for much of the interview schedule for the current project, there is always a danger of the data being tainted by 'acquiescence bias'. This is the phenomenon of agreeing with someone in real or perceived authority without due consideration of one's own views. To minimise this, interviews eschewed yes/no questions ('Do you like this feature?') in favour of open questions ('What else would you like to see?')

The survey consisted of 12 questions, relating first to technology use generally, and then specifically to experience of using CVT Connect. Two of these required a free-text response (and as such, were answered by fewer respondents, 30 and 31 respectively, of 53 in total):

- Please tell us about any problems you might have using your device (such as turning it on, viewing the screen, remembering passwords etc.)

- Are there any new features you would like to see on CVT Connect?

A link to the survey was distributed directly to participants, internally, though local administrators, who made direct contact, explained the research and asked people if they would like to complete it. 
They then either shared the link or set up the link to the survey for people (i.e. on tablets supplied by CVT or their own devices).

\section{Ethical issues}

Several ethical issues arise, both in the design and use of the platform itself, and in the data gathering. With regard to the former, three major issues were privacy, safety and freedom of expression. The first two of these went hand-in-hand. In addition to the platform only being open to CVT residents and staff, users were not permitted to include telephone or other contact details (hence calls for 'chat' facilities described later). Photographs are vetted before posting, partly on the grounds of decency or safety and comments are moderated - which raises the issue of freedom of expression. Social media has become famous for being an outlet for personal anger, frustration or other negative emotions - and in a wider programme of research one of the present writers Williams [16] found various examples of supporters reporting petty disputes began or fuelled by online exchanges. Thus, it was considered ethically justifiable to monitor and remove posts if considered offensive or inflammatory. Finally, participation was voluntary. Whilst CVT as an organisation was very enthusiastic about the platform, creating CVT Connect champions and allocating support time to its promotion and use, creating an account was purely voluntary. News and other information from CVT are never exclusively disseminated via the platform and, whilst demonstrating its functionality and potential benefits, there is no element of coercion or negative outcomes in declining.

With regard to the ethical issues arising in the data gathering itself, a major issue is that of obtaining informed consent. This implies an understanding of the research aims, the data gathering (and analysing) process in general, and what involvement entails for specific individuals. The research aims were explained in terms of exploring the use, benefits, barriers and future development of CVT Connect, in order to take into account the views of participants to improve the platform. Data gathering was described (accurately!) as a chat with someone interested in and working on the use 
of technology by the cohort, and recruitment material and a participant information booklet were drawn up by the external researcher (Williams) and members of the CVT support team and potential participants. Although not formally employed, CVT has a self-advocacy 'easy-read' production group who help ensure that any information produced for people with learning difficulties conforms with the Accessible Information Standards. 'Informed consent' implies the right to deny consent. Thus, as with using the CVT Connect platform itself, the voluntary nature of participation was emphasised. It is important to say here that the research was approved by the UCL Ethics Committee (Project ID Number 0343/005) for which the right to refuse or withdraw participation was essential.

\subsection{Results}

Note that the interview results aren't expressed quantitively (e.g. 'eight people said...' etc.) This is for several reasons. First, participants were very heterogeneous, both in terms of demographic details, and in their experience with and knowledge of digital media etc.. Thus, even where many people made the same point they were doing so from very different circumstances and perspectives. Second, there were only nine interviewees - far too few to determine the strength of opinion. That was attempted in the survey. The focus was more on simply eliciting the issues, regardless of how many participants raised them. Nevertheless, it would be impossible to discuss a particular point without using phrases such as 'some participants', 'one person', 'several people' etc. unless the subject was removed by use of the passive voice throughout ('it was stated that ...'). Hence these quantifiers being used in the research.

Device ownership: Less than half of survey respondents (45\%) use a smartphone, and only just over a quarter (27\%) own a laptop, although nearly three quarters (73\%) use a tablet. A majority of interviewees used a smartphone, however, although, of course, those who did so were more likely to volunteer to participate in the study. A support worker interviewed said that 'most of the people we support have access to mobile phones', although these were not necessarily Internet enabled; and another observed that: 'The community has a wide range of people, with a big variation being in 
age. The more youthful ones have everything. ... there is even one PWS ['person we support'] with a smart watch. The older ones are not bothered about the technology'

Activities - general: The most popular telephone activity amongst survey respondents was to use their devices in the traditional way - to make calls (77\%) and texts (65\%). These were far more popular than using the Internet 'apps' WhatsApp or Messenger. Reflecting this was the relatively low use of social media. Less-Fewer than a third of respondents reported using Facebook or Instagram on their phones. This was also reflected in use of tablet computers. Indeed, reported use of social media was even lower, at $19 \%$. The most popular activity on these devices was 'to find information' (61\%), followed by taking photographs (59\%) On a phone, these activities were also popular (55\% and $45 \%$ respectively).

It was possible to explore activities more with those who were interviewed. A wide variety of information-seeking was elicited, including finding information about holidays, weather, bus times, and enjoying popular culture such as television soap-operas and music. One person kept up with the activities of a learning-disabilities organisation called 'Kingfisher Treasure Seekers'

(https://www.kftseekers.org.uk/). Game activities and watching YouTube were also reported by interviewees. As with survey respondents, the use of social media was low, although WhatsApp and Messenger were mentioned. One interviewee remarked: 'I have heard of Facebook, but I don't use it. I don't really know how to do it', and another said that 'You hear lots of negative things in the media about it'. A third, however, claimed to have 425 Facebook 'friends', including old school and college acquaintances, church contacts etc. most of whom he knows 'in real life'.

CVT Connect use: The first survey question specifically related to CVT Connect asked (logically) whether respondents had seen it. Ninety percent had done so, with another $8 \%$ hearing about it but not seeing it at the time of the survey. Nearly a half (44\%) had completed a personal profile, with a further $42 \%$ having done so, minus the 'personal goals' section. Visits by the writers to the various CVT centres to witness and participate in training sessions suggested that this element of one's 
personal profile was very difficult. This was for two reasons. First is the time element - the requirement is to formulate at least one goal to achieve within each of the periods, three months, six months and one year. Determining what is achievable within each particular time frame is quite a challenge. Second, the goals have to be 'measurable' in that it must be possible to say when they have been accomplished. Thus, 'get better at using money' is not an appropriate goal (in this sense, at least) but 'buy something from a newsagent using the correct change' would be. Staff spent considerable time helping people formulate these.

As regards use by staff, one supporter opined that 'No staff use it properly. Fewer than ten, out of more than 30 staff have profiles, and those who have, made them because they were asked to signup'. Many staff (as can be seen by their profiles, in fact) have not gone further than create a personal profile. The reasons for this lack of engagement are outlined in the section on 'barriers', below.

The survey asked what other activities had been undertaken on CVT Connect. More than a half (51\%) had posted something, but only $12 \%$ had looked at any other 'walls', and only $9 \%$ had looked at the noticeboard. An important element of CVT Connect (just like other social media platforms) is that of sharing one's profile. Twenty eight percent said they did this Interviewees (who for various reasons including lack of Internet access or device or, in one case, not remembering a password) reported various levels of engagement, from having a full profile page with personal goals and making contributions to various subject walls ("I have put my hobbies on it. I like drama"), to only browsing the contributions of others (valuable in itself) to having a page but not actually engaging with it.

Despite a general low staff take up mentioned above, those who have engaged mentioned various efforts and initiatives. One has contributed much to the 'Walls' - in particular the one on Food and Recipes, to which she has contributed. 'I use this wall a lot as I enjoy cooking. I use it in particular when cooking with one person we support [on a one-to-one-basis]. I post pictures of what she has 
made. She craves one-to-one attention, and this is a useful and constructive way to give that time. Think posting picture of what she made may help with self-esteem'.

Another support worker tried to set up a community Cultural Club Wall on CVT Connect, to post timetables and posters of events. He imagined 'a sort of notice board of events and info for general on-line access to support the paper copies and word of mouth in the community'. However, he found that there was a limit to the size of documents that can be uploaded, and was not able to realise the idea.

CVT Connect benefits: It was possible in interviewee sessions to explore the benefits of CVT Connect. As the system was taught in group sessions, and for almost all participants, initial postings and viewings undertaken in this social environment, many of the benefits articulated relate to this aspect, rather than of the system itself or of solo use of it. Thus, for one person it was 'really good fun', especially as there were 'always' six to eight people present. For another, 'the sessions are good also because I do other things on the computer at the same time'. This was witnessed, along with the dynamic nature of these, where those present showed each other their activities. Another benefit of the group was that the support worker is present, and so the group members 'always get help'.

The benefit of CVT Connect in its role as a virtual social connector did not go unrecognised.

One felt that it was 'a good social platform to make friends at different communities'. Part of its appeal is that 'it's a secure chat group' and also that 'people can post achievements'. This is significant, as social isolation is an issue for most people with a disability. Recent research collated by the UK mental health charity Mencap [17] suggests that over half of disabled people reported feeling lonely, including $77 \%$ for those aged $18-34$, and a third of young people with a learning disability spend less than one hour away from their home on a typical Saturday. Similarly, over half of working age disabled people who have felt lonely in the past year said they experienced depression. (62\%) and anxiety (58\%) 
The closed, in-house environment of the platform was also seen as a benefit, with CVT Connect being protected from people from outside the organisation, especially considering there is much research evidencing cyber-bullying and other serious problems with public social media services (e.g. Kowalski et al, [18] and Biram, [19]). People Supported are able to follow the people who support them. By contrast, CVT policy prohibits supporters from being 'friends' with those they support, on the public platform Facebook. One supporter described people supported attempting to befriend or follow supporters as 'a big problem' and 'almost like stalking'. Apart from 'following' supporters, and being able to read and 'like' their posts, there is also an 'Ask Huw' facility. Huw John is Chief Executive of CVT and answers questions on CVT Connect. Recent questions to him have included a request for a new bike rack at one of the communities (answered by reference to possible ways to fund it) and an invitation to visit a craft workshop.

Staff noted many more actual and potential benefits. One of these related to time given by staff in their support roles. One interviewee said that CVT Connect could be used to aid social interactions and promote discussion, or as a learning tool: 'as when I and a PWS find out about things [such as] where they are going on holiday, e.g. the camel as ship of the desert or desert transport for [the PWS] going to Morocco'. Another said, similarly, that such a conversation could be around goals, interests or content to create and post on the wall. The private wall could be used for posting photos of things/ people that are important to the person supported, and could perhaps be used for reassurance in times of stress. It was suggested that the non-photo wall could be used as a diary for important dates.

Another benefit highlighted by staff was the facility to disseminate community information (although, as mentioned in the barriers section below, there were technical problems with aspects of this). By having the CVT Connect account, 'we can advertise events in the group to let the PWS know what's happening and when rather than relying on word of mouth'. Thus, as another interviewee mentioned, if one of the people supported is organising an activity it can be put on the appropriate wall. Some examples of where this has been done include a visit to see the Lion King. 
BBQs are also advertised on CVTC. These activities involve everyone coming together and interacting 'which is the idea, of course'.

Of course, there were not only benefits to using CVT Connect, but barriers too, ranging from usability issues to time constraints or a failure to see any of the benefits others articulated. These are discussed below.

CVT Connect barriers: In addition to asking specifically about CVT Connect, barriers to the use of mobile devices were explored using a survey question requiring a free-text answer, and in interviews. By far the most prevalent survey response related to remembering passwords, with 12 out of 30 people (40\%) who completed this answer (only $59 \%$ of all respondents, as free-text may have been burdensome for some people) mentioning this aspect of technology use. One respondent admitted to having to 'write them down so I remember. I leave a safe list at home'. Another wrote that problems were 'due to the number of them and they have to be more complex nowadays'. In one case problems remembering passwords resulted in 'new accounts' being opened, with (presumably) the one not accessible being discarded.

Difficulties were also experienced with regard to configuration/settings including setting a background, 'tidying' apps and updating the device. One respondent needed help setting up the interface to accommodate dyslexia. The small screen size was noted. The latter was also mentioned by interviewees, one of whom felt that his tablet was better for most activities because it was bigger and therefore easier to use.

Respondents were asked to describe 'any problems you have had in using CVT Connect'. As with the earlier question, difficulties with passwords dominated responses, with over a quarter (26\%) of those answering mentioning this. Apart from responses indicating that passwords were difficult to remember, one person said s/he needed support, another said that having dyslexia exacerbated the problem, and a third that it needed to be reset. One person reported forgetting their user name. Staff interviewed also reported problems with the passwords of the people supported, and often 
had to help reset. One opined that some people will never remember their passwords 'in a million years'. However, there is a CVT general policy which states that support staff should not hold people's passwords. Interviews with support staff, however, showed a tension between policy and practice.

Technology is always advancing, of course, and it is now possible to use iris or fingerprint recognition - both of which can now be found in the latest mobile phone devices. Whilst this solution would be ideal, the cost and technical expertise required to incorporate either of these features into CVT Connect would be prohibitive.

Another problem concerned the set-up of the system. Ten per cent of respondents mentioned problems with uploading photos. This appears to be a small number, but represents nearly a fifth (18\%) of those reporting that they had added content, and possibly a greater percentage of those who had attempted do so and been unable. In fact, file (and therefore photo) sizes are limited, so some photos are rejected by the system. Another problem around images was elicited during observational sessions. Pictures downloaded from the Internet are saved by default, on one person's device, to the desktop rather than to 'My pictures'. it thus took a long time to find it. The same person also forgot that each image had to be approved, so even when it had been successfully saved, it needed to be placed in a 'shared resources' location (from where it could be chosen for display). However, even after doing this, it is not available for display until it has been approved by an appropriate member of staff - making the process rather complicated.

Similarly, a staff member interviewed tried to upload photos but found that those she has taken were too big, in terms of computer memory consumed, for the system to accept. On one occasion she took a photo of some flowers in her garden, but it was not possible to upload this onto the CVT site, so she had to use Google to find a comparable picture.

Other difficulties were mentioned by small minorities in the survey free-text answers. Apart from one person indicating that the text was too small, other barriers noted did not relate directly to the 
system itself. They included 'Typing words'. This was only mentioned by one respondent, possibly because of the self-selecting sample and the fact that in some cases a support worker aided the survey completion. The need for more support was mentioned (comments were "I do not use it as no one helps me"; "I get confused and need help", and "Need staff help" L. Finally, one person complained of a lack of engagement by friends, and another that there was no reason to use it highlighting the need for a 'critical mass' to be established. It is hoped that this will create a snowball effect whereby increased users leads to increased posts and increased interest by others.

Staff interviewees spoke of barriers beyond those encountered in using the system. One contextual barrier was that of staff attitudes, both to technology in general and CVT Connect in particular. With regard to the former, one staff member interviewed said that, 'people - including staff - don't like change, which stops them adopting new technologies.... I find it's not an age thing - it's just how people are, you either like technology and move with the times or you have technology because everyone else does or your generally not bothered'. Regarding CVT Connect, one felt that people supported have 'a lot of outgoing social activity already'. However, this assertion was contested by a senior member of staff during an informal process of member-checking, and no other supporter interviewee felt that the lives of the cohort were too busy to accommodate CVT Connect.

Another theme, described as 'the biggest constraint' identified was 'the competing demands on staff and lack of time'. One staff member charged with promoting it tried to tell colleagues that in the long term it will help staff save time, as it will be a new way to communicate with people supported and to share different aspect of life, such as interests, goals, etc. Thus, the people supported could view staff as 'friends' on CVT Connect, unlike on other social media where, as noted above, there is a policy of non-engagement.

CVT Connect new features: Survey respondents were asked if there were any new features they would like to see on CVT Connect. The most prevalent answer followed the final theme from the question on barriers - a desire to see more friends (and in one case, a greater presence by staff) on 
the platform. Similarly, more walls were suggested, of both specified content ('joke wall and good support wall'; 'nature page, weather page or a news one'; 'Places where you can walk') or of unspecified content ('More walls, covering more subjects'; 'Anything nice interesting and good'; 'more photographs'). Clearly, all this could happen with more contributing participants. Other potential content included a jobs page and a noticeboard (the latter does exist, in fact).

A chat facility was also requested by one of the staff, who pointed out that it would be good for people to be able to communicate across communities. One person had lived at a different community in the past, for example, and it would be good for that person to be able to maintain contacts across sites.

Another recommendation from staff was that all 'Wall' entries could be tagged with the contributors' community locations. This would be helpful, as people with similar interests could arrange to get together when they see others' wall postings, if that were possible: 'People are nosey and want to know where the posts are from'.

CVT Connect lessons / Next Steps: The aim for CVT Connect is to continue building user numbers, growing networks and encouraging people to use the different functions. New features will be added to ensure the site evolves to engage a wider user base. This is a recognition that any social media site should ever be static or regarded as complete. New features that enhance and improve the user experience are required whatever the platform. To support this commitment, CVT have funded eight hours per month to develop the site, as informed by the research feedback.

Taking lessons from the study findings, the ability to set personal goals and celebrate achievements is an important feature of the profile section. The addition of timescales, although usual in social care settings, does not lend itself to the more informal setting of a social media platform and could be removed, although the danger of forgetting not being motivated to complete them would need to be addressed. Also, recognition of achievements from others is significant. One option is to add 
'awards' that can be given by administrators i.e. 'Recipe of the month' or 'Frequent user'. This then elevates the status of users and gives a further level of interest to both staff and people supported.

The personal profile is the natural starting point for people registering. There is a temptation for users to skip this stage and start exploring without first fully developing a profile. To obviate this problem there needs to be continued work to encourage people to develop and share their profiles to a minimum standard. This then supports the platform being 'social' rather than just a place to find information with minimal engagement with others.

Findings suggested that the platform can be over complex and restrictive, especially with regard to the current requirement that images need to be approved before they can be added to the site. This is being removed allowing users to directly add to their post. Images and content will still be monitored by the local administrators to ensure that people remain safe and do not share confidential information or images that may increase their on-line vulnerability. However, image size will still be limited to $2 \mathrm{MB}$ due to server size restrictions and speed of processing.

The addition of a 'like' button to posts has enabled people to respond positively. We are considering additional features that may support a conversation thread to begin between interested users. Another consideration is how the technology can be used to enable people to post without having to type on a keyboard. Some people are already using existing features on their devices to convert spoken word into text which is added to posts. We are looking at the possibility of adding a function that will also enable a person to listen to posts from others.

There is a temptation to focus on the functional aspects such as noticeboards and events. CVT connect has to be a 'fun' and engaging platform to visit. As noted above, the suggested new features include pages where people can post jokes, possible activities and other similar material.

Finally, it is a particular challenge to get staff to engage, mainly because of time constraints but also in terms of their own support for the platform. It is vital they do so, however, as they are the constant source of support that can encourage and help people develop the skills they require and 
the confidence to explore the platform and locate all the various features. To enable this, one idea is to add a weekly diary sheet to each supported person's personal profile, which they themselves could complete. Staff would also have a diary sheet in the form of a rota that will show who they are supporting and when. Once populated the two would link together providing an updatable diary for the people supported. They could then access each other's personal profile through CVT Connect.

The balance will be in maintaining CVT Connect as a 'social platform' without it changing focus to become a care management tool supporting the functional aspects of support.

\section{Conclusion}

This study has shown that it is possible to involve people with learning disabilities in the design and development of an electronic resource, and that a safe, protected social media platform can be utilised for both entertainment and education. Creating and reading posts was described as 'fun', and the potential maintain contact with and make new friends highly valued. Staff exploited the medium to focus discussion on a one-to-one basis, and to disseminate community information However, careful consideration needs to be given to various aspects of its functionality which proved difficult (photo uploading and remembering passwords). Also, the reticence of some staff to be involved highlighted the need both for training and for scheduling sufficient time for active participation. The overall aim of the platform is, of course, to enhance the lives of the people with learning disabilities. If there is accumulating evidence of this, be it in terms of greater engagement with friends, acquiring new hobbies or keeping up to date with community events, hopefully even the most technophobic staff will wish to be part of the initiative.

\section{Acknowledgements}

The study reported here is part of a programme of research being generously funded by The British Academy as a Post-doctoral Fellowship awarded to Pete Williams, who would also like to thank his steering group, Prof. Barrie Gunter, Dr Andrew MacFarlane, Dr Mina Vasalou, Dr Rob Miller and (during Rob's sabbatical) Prof. Elizabeth Shepherd, for their invaluable help and advice. He is most 
grateful too, of course, to Camphill Village Trust whose directors invited him to participate in CVT Connect, and all the participants and supporters at the CVT sites where the research was undertaken.

\section{References}

[1] Battisby, A. (2019) The Latest UK Social Media Statistics for 2019

\section{https://www.avocadosocial.com/latest-social-media-statistics-and-demographics-for-the-uk-in-}

$\underline{2019 /}$

[2] Darragh, J., Reynolds, L., Ellison, C. and Bellon, M. (2017). Let's talk about sex: How people with intellectual disability in Australia engage with online social media and intimate relationships.

Cyberpsychology: Journal of Psychosocial Research on Cyberspace11(1) Available at:

http://dx.doi.org/10.5817/CP2017-1-9 (accessed 15.05.19)

[3] Caton, S. and Chapman, M. (2016) The use of social media and people with intellectual disability: A systematic review and thematic analysis, Journal of Intellectual and Developmental Disability, 41(2) pp.125-139

[4] Kydland, F., Molka-Danielsen, J., Balandin, S. (2012). Examining the use of social media tool 'Flickr' for impact on loneliness for people with intellectual disability. In T. Fallmyr (Ed.),NOKOBIT2012: Proceedings of the 2012Norsk konferanse for organisasjoners bruk av informasjonsteknologi Trondheim, Norway: Akademika forlag pp. 253-264

[5] Molin, M., Sorbring, E., Löfgren-Mårtenson, L. (2015) Avd för psykologi och organisationsstudier, Högskolan Väst, Avd för socialpedagogik och sociologi \& Institutionen för individ och samhälle, Teachers' and parents' views on the Internet and social media usage by pupils with intellectual disabilities, Journal of Intellectual Disabilities, vol. 19, no. 1, pp. 22-33.

[6] Holmes, K. M., \& O'Loughlin, N. (2014). The experiences of people with learning disabilities on social networking sites. British Journal of Learning Disabilities, 42, 3-7. 
[7] Shpigelman C, Gill CJ (2014) How do adults with intellectual disabilities use Facebook?, Disability and Society, 29(10) pp.1601-1616

[8] Daems, J. Dekelver, J. De Vliegher, A. Smets, J. Martens, L (2015). Able to include: focus groups with persons with IDD and their coaches communicating through social media, in2015 Conference on Raising Awareness for the Societal and Environmental Role of Engineering and (Re)Training Engineers for Participatory Design (Engineering4Society), Leuven, pp. 76-79.

[9] Blanco, T., Marco, A. and Casas, R. (2016) Online Social Networks as a Tool to Support People with Special Needs. Computer Communications 73 (2016): 315-31.

[10] Daems, J., Dekelver, J., De Vliegher, A., Smets, J. \& Martens, L. (2015) Able To Include: Focus groups with persons with IDD and their coaches communicating through social media: Raising Awareness for the Societal and Environmental Role of Engineering and (Re)Training Engineers for Participatory Design Engineering4Society Conference Proceedings pp. 76-80

[11] Williams P (2019). Facebook use by people with learning disabilities: The case for facilitated, guided autonomy. New Trends and Issues Proceedings on Humanities and Social Sciences, 6(5), pp.99-108.

[12] Williams P (2019) Smartphones and people with learning disabilities: self-reported barriers to effective usage. Proceedings of the International Academic Conference on Teaching, Learning and Elearning in Budapest (IAC-TLEI), Budapest, Hungary, on March 15 -16, 2019. pp.7-16

[13] Williams P Shekhar S (2019) People with learning disabilities and smartphones: testing the usability of a touch-screen interface Education Sciences 9(4) e263

[14] Perry J (2004) Interviewing people with intellectual disabilities in Emerson, E. (2004). The international handbook of applied research in intellectual disabilities. Chichester, West Sussex, England ; Hoboken, NJ: Wiley.pp.115-132 
[15] Prosser H, Bromley J. (1998) Interviewing people with intellectual disabilities. In E. Emerson, C. Hatton, J. Bromley, A. Caine, E. Clinical psychology and people with intellectual disabilities New York, NY, US: John Wiley \& Sons pp.99-113

[16] Williams, P. (2019). Facebook use by people with learning disabilities: The case for facilitated, guided autonomy. New Trends and Issues Proceedings on Humanities and Social Sciences 6(5), pp.99108.

[17] Mencap 2018) Friendships Available at: https://www.mencap.org.uk/learning-disabilityexplained/research-and-statistics/friendships

[18] Kowalski, A., Limber, A., Patricia, W. and Limber, S. (2012) Cyberbullying : Bullying in the Digital Age / Robin M. Kowalski, Susan P. Limber, Patricia W. Agatston. Chichester: Wiley-Blackwell, 2nd ed. [19] Biram, T. (Ed.) (2019) Cyberbullying Cambridge: Cambridge University Press 
Table 1: CVT Connect problems and solutions implemented

\begin{tabular}{|c|c|c|}
\hline Aspect & Problem & Solutions implemented \\
\hline Password & $\begin{array}{l}\text { People struggling to remember } \\
\text { written passwords. }\end{array}$ & $\begin{array}{l}\text { Option to create a password } \\
\text { containing three images from a } \\
\text { menu. }\end{array}$ \\
\hline Email back up & $\begin{array}{l}\text { If people forget passwords it } \\
\text { can be reset with a prompt to } \\
\text { back up email. Problem is } \\
\text { people often forget email } \\
\text { passwords as well. }\end{array}$ & $\begin{array}{l}\text { Local administrator can reset } \\
\text { password and contact people direct } \\
\text { to advise how to log back in. }\end{array}$ \\
\hline Lack of direct support & $\begin{array}{l}\text { People need support to use CVT } \\
\text { Connect until they become } \\
\text { skilled and familiar. }\end{array}$ & $\begin{array}{l}\text { Support staff sign up and offer } \\
\text { regular individual and group support } \\
\text { sessions to use the platform. }\end{array}$ \\
\hline Site Navigation & $\begin{array}{l}\text { Users need support to navigate } \\
\text { site where multiple choices are } \\
\text { presented. }\end{array}$ & $\begin{array}{l}\text { Addition of 'prompts' on tool bar } \\
\text { showing users where new activity is } \\
\text { since last log in. } \\
\text { Add a 'dashboard' that prompt } \\
\text { users to navigate to recent activity. }\end{array}$ \\
\hline Hardware (lack of) & $\begin{array}{l}\text { Not every person with a } \\
\text { learning disability has access to } \\
\text { laptop or smart devices. }\end{array}$ & $\begin{array}{l}\text { Central provision of devices to } \\
\text { encourage first time users. }\end{array}$ \\
\hline $\begin{array}{l}\text { Individual IT skills } \\
\text { lacking }\end{array}$ & $\begin{array}{l}\text { This is many people first } \\
\text { experience of using this type of } \\
\text { digital platform, basic skills } \\
\text { lacking }\end{array}$ & $\begin{array}{l}\text { Staff designated as CVT Connect } \\
\text { champions tasked with running } \\
\text { individual and group IT sessions. }\end{array}$ \\
\hline $\begin{array}{l}\text { Internet Safety } \\
\text { concerns }\end{array}$ & As above & $\begin{array}{l}\text { As above, also introduction of a } \\
\text { 'staying safe online' easy read } \\
\text { guide. }\end{array}$ \\
\hline $\begin{array}{l}\text { Stimulating Interest in } \\
\text { the platform. }\end{array}$ & $\begin{array}{l}\text { Need a critical mass of users to } \\
\text { ensure site remains lively and } \\
\text { engaging. }\end{array}$ & $\begin{array}{l}\text { Create different themed areas } \\
\text { around subjects that people said } \\
\text { would interest them. i.e. lifestyle, } \\
\text { activity, health etc.. Add also } \\
\text { sections for local activity as well as } \\
\text { charity wide information. } \\
\text { Enhance the 'personal profile' so } \\
\text { that it includes a personal goal } \\
\text { setting function and achievement } \\
\text { wall. } \\
\text { Add a 'like' button so that people } \\
\text { can acknowledge they have seen a } \\
\text { post. }\end{array}$ \\
\hline Maintaining Interest & $\begin{array}{l}\text { Need users to visit regularly and } \\
\text { grow the sites content. }\end{array}$ & $\begin{array}{l}\text { New features constantly added } \\
\text { including new themed areas, goal } \\
\text { setting, competitions, profile } \\
\text { sharing. }\end{array}$ \\
\hline
\end{tabular}

Table 9: CVT Connect problems and solutions implemented 


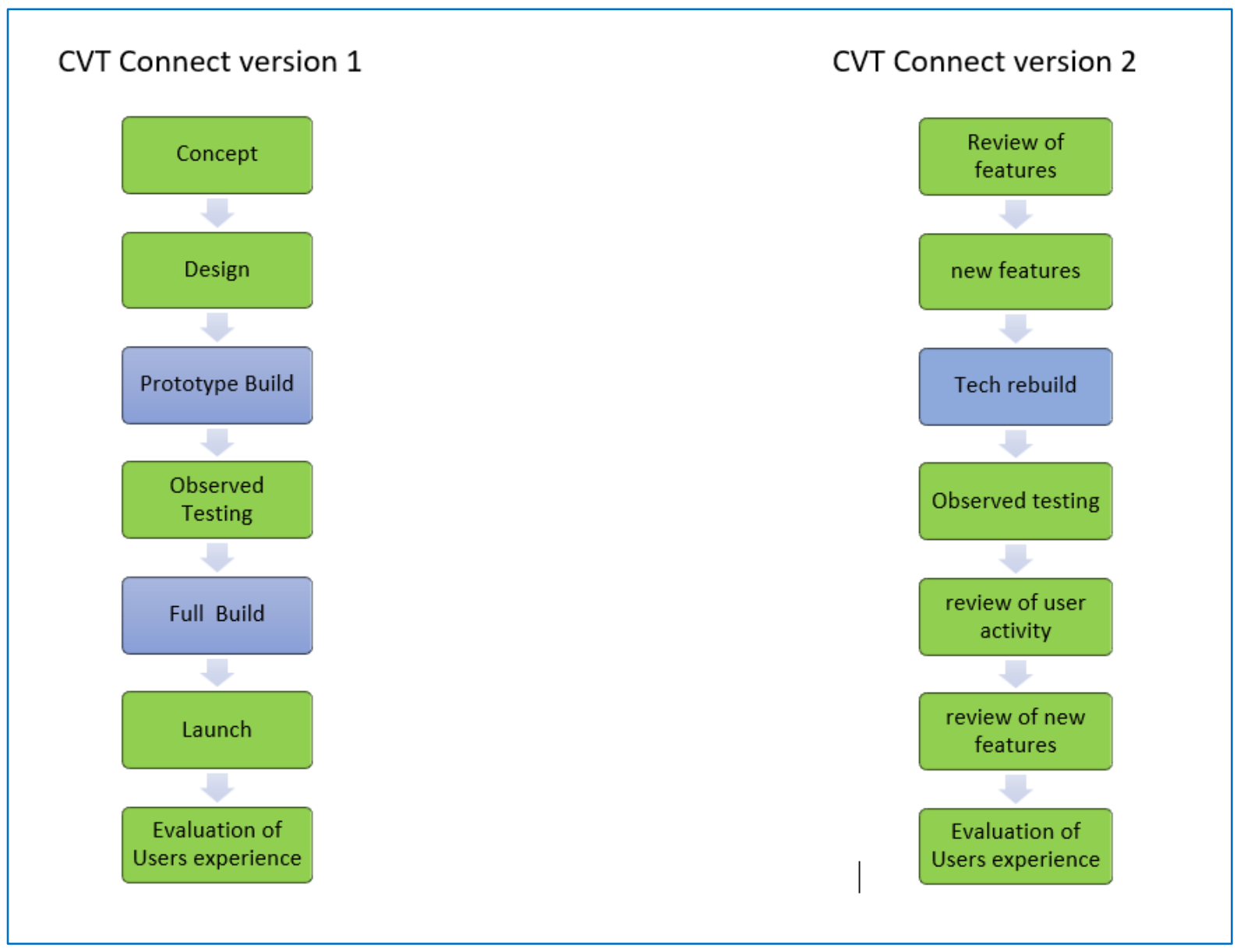

